\title{
Sound transmission by cartilage conduction in ear with fibrotic aural
}

\section{atresia}

\author{
Chihiro Morimoto, MD; Tadashi Nishimura, MD, PhD; Hiroshi Hosoi, MD, PhD; Osamu Saito; Fumi Fukuda; \\ Ryota Shimokura, PhD; Toshiaki Yamanaka, MD, PhD \\ Department of Otolaryngology—Head and Neck Surgery, Nara Medical University, Nara, Japan
}

\begin{abstract}
A hearing aid using cartilage conduction (CC) has been proposed as an alternative to bone conduction (BC) hearing aids. The transducer developed for this application is lightweight, requires a much smaller fixation force than a BC hearing aid, and is more convenient to use. CC can be of great benefit to patients with fibrotic aural atresia. Fibrotic tissue connected to the ossicles provides an additional pathway (termed fibrotic tissue pathway) for sound to reach the cochlea by means of CC. To address the function of fibrotic tissue pathway, BC and CC thresholds were measured in six ears with fibrotic aural atresia. The relationship between the CC thresholds and the results of computed tomography was investigated. In the ears with the presence of a fibrotic tissue pathway, the CC thresholds were lower than the BC thresholds at 0.5 and $1.0 \mathrm{kHz}$. At $2.0 \mathrm{kHz}$, no significant difference was observed between the BC and CC thresholds. The current findings suggest that sound in the low to middle frequency range is transmitted more efficiently by CC via a fibrotic tissue pathway than BC. The development of hearing devices using CC can contribute to rehabilitation, particularly in patients with fibrotic aural atresia.
\end{abstract}

Key words: acquired aural atresia, airborne sound, binaural hearing, bone-anchored hearing aid, bone conduction, external auditory canal, fibrotic tissue pathway, hearing aid, occlusion effect, soft tissue pathway.

\section{INTRODUCTION}

Hearing loss results in reduced communication in daily life and is a major factor contributing to reduced quality of life. Aural atresia is a hearing disorder that is difficult to treat. Conventional hearing aids using air conduction (AC) provide little benefit because of the fixation problem, feedback oscillation, and insufficient gain [1]. Methods of intervention include surgical treatment or fitting of bone conduction (BC) hearing aids [2]. However, surgical treatment involves the risk associated with the operation [3-4] and sometimes results in the stenosis and lateralization of the repaired ear canal and worsened hearing improvement after long-term observation [5-6]. For BC hearing aids, the transducer has to be tightly pressed against the mastoid [2] or directly fixed with an attachment screw embedded in the bone, referred to as a bone-anchored hearing aid [7-8]. Unfortunately, both methods involve disadvantages. For conventional BC hearing aids, the transducer has a relatively large mass and a large fixation force is needed for the device to function properly. Long-term use can also cause skin irritation, long-continued depressions in the skin, and discomfort [2]. For bone-anchored hearing aids, surgery

\footnotetext{
Abbreviations: $\mathrm{AC}=$ air conduction, $\mathrm{BC}=$ bone conduction, $\mathrm{CC}=$ cartilage conduction, $\mathrm{CT}=$ computed tomography, $\mathrm{ISO}=$ International Organization for Standardization.

*Address all correspondence to Tadashi Nishimura, MD, PhD; Department of Otolaryngology — Head and Neck Surgery, Nara Medical University, 840 shijo-cho Kashihara, Nara 634-8522, Japan; +81-744-22-3051; fax: +81-744-246844. Email: t-nishim@naramed-u.ac.jp
} http://dx.doi.org/10.1682/JRRD.2013.05.0128 
is required, the portion of the implant exposed to open air can induce infection, and some cases require revision surgery because of skin overgrowing the abutment [9-10].

Hosoi found that a clear sound can be heard when a vibration signal is delivered to the aural cartilage from a transducer [11]. This form of signal transmission is referred to as cartilage conduction (CC). Using CC, a novel hearing device was developed for patients with conductive hearing loss and for whom a conventional AC hearing aid was not effective [12-13]. A later study demonstrated the superior benefit of a CC hearing device, especially in patients with postoperative aural atresia [14]. These results suggest that novel hearing devices can be developed using $\mathrm{CC}$ as an alternative to $\mathrm{BC}$ in hearing aids and other audiological instruments.

When the CC transducer is placed on the aural cartilage, sound is transmitted to the cochlea via three possible routes in an anatomically normal ear (Figure 1(a)). In the first pathway, vibrations of the transducer produce airborne sounds, some of which reach the ear canal and are transmitted to the cochlea via the conventional pathway for AC. Such stray sound is also radiated by BC transducers [15-16]. This pathway is termed direct AC. In the second pathway, vibrations of the aural cartilage
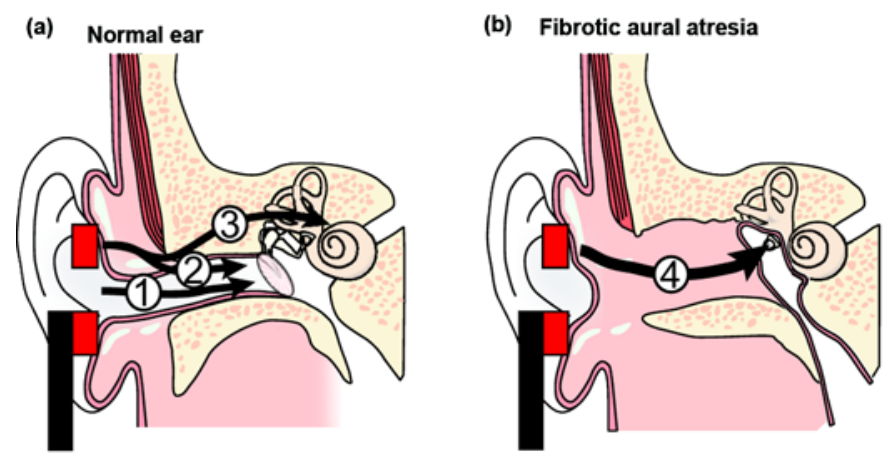

(1) Direct air conduction

(3) Cartilate bone conduction

(4) Fibrotic tissue pathway

Figure 1.

Sound transmission pathway of cartilage conduction. (a) In normal anatomical ear, sound is transmitted to cochlea via three possible routes. (b) In ear with fibrotic aural atresia, fibrotic tissue in ear canal blocks air conduction. However, if fibrotic tissue is connected to ossicles, sound is transmitted via connection to cochlea. This fourth pathway is termed fibrotic tissue pathway. are transmitted to the cartilaginous portion of the ear canal. These vibrations induce an acoustic signal in the canal that is transmitted by AC to the eardrum. This pathway is termed cartilage AC, which is a different pathway that is not part of either the AC or BC pathways. In the third pathway, vibrations of the aural cartilage are transmitted to the cochlea via the skull bone. This pathway is termed cartilage BC.

There are important differences between the proposed method of delivering sound by means of CC and the conventional method of delivering sound by means of BC. A major difference between CC and BC is the fixation position of the transducer. CC allows for a small, lightweight transducer to be placed conveniently on the aural cartilage for sound transmission. In $\mathrm{BC}$, the fixation position is either the mastoid or forehead bone, which is some distance from the ear. There is also the problem of transcranial transmission with BC. The precision of transducer placement is also not well controlled for mastoid placement, leading to relatively large test-retest variability in BC measurements. A second, more important difference is the fixation force. A small fixation force of $0.06 \mathrm{~N}$ is sufficient for sound transmission with a CC transducer. In contrast, a BC transducer requires a fixation force of $5.4 \mathrm{~N}$, which is almost one hundred times larger and is a source of discomfort in BC hearing aids.

In an ear with aural atresia, most of the airborne sound in the ear canal cannot reach the cochlea as with direct AC. There is, however, an additional pathway for CC in an ear with fibrotic aural atresia. In a previous study by Nishimura et al., the ear canal was occluded with fibrotic tissue, not bony tissue [14]. In addition, the fibrotic tissue was connected to the stapes, thereby providing a fourth pathway for CC sound to reach the cochlea. This fourth pathway in fibrotic aural atresia is termed the fibrotic tissue pathway of CC (Figure 1(b)). Nishimura et al. obtained a large gain below $2 \mathrm{kHz}$ in patients with a fibrotic tissue pathway using the prototype CC hearing aid [14].

This observation led to the underlying rationale for the current study. We hypothesized that for those ears showing a fibrotic tissue link to the ossicles, the CC threshold will be lower than that for $\mathrm{BC}$ at frequencies below $2.0 \mathrm{kHz}$. In order to test this hypothesis, BC and CC thresholds were measured for outpatients in our hospital with fibrotic aural atresia that had already been diagnosed using computed tomography (CT) scans. 


\section{METHODS}

Six patients with acquired aural atresia participated in the study. The Table shows the characteristics of the subjects. Their ear canals were occluded with fibrotic tissue, which was induced after surgical operation in five subjects. By chance, the laterality of the aural atresia was right in all subjects. The experimental procedure was approved by the ethics committee of Nara Medical University. Participants provided written informed consent.

The thresholds of AC and BC were measured by a conventional pure tone audiometer (AA-78, Rion Co, Ltd; Tokyo, Japan). The AC and BC stimuli were presented to the ear and mastoid using earphones (AT-02, Rion Co, Ltd) and a bone vibrator (BR-41, Rion Co, Ltd), respectively. The earphones and bone vibrator were calibrated with a sound pressure meter (AG-64, Rion Co, Ltd) and artificial mastoid (type 4930, Brüel \& Kjær; Nærum, Denmark) according to International Organization of Standardization (ISO) 389-1:1998 and ISO 3893:1994, respectively [17-18]. For CC, the transducer was placed on the cavity of the concha except for subject 3. In subject 3 , it was fixed on the tragus with a commercial tape because it could not be hung on the cavity of the concha because of postoperative deformation. The property of the transducer is described later.

Thresholds were obtained at frequencies of $0.5,1.0$, 2.0, and $4.0 \mathrm{kHz}$, respectively. Tone bursts of $300 \mathrm{~ms}$, including rise and fall ramps of $50 \mathrm{~ms}$, were employed for the stimulus. The signals were generated by a function generator (WF1946, NF Corporation; Yokohama, Japan), and the intensity was controlled by a programmable attenuator (PA5.0, Tucker-Davis Technologies Inc; Alachua, Florida). The threshold was determined by the same ascending method as in conventional audiometry. The opposite ear was masked by a narrow band noise using a plateau method. The experiment was performed in a soundproof room.

Figure 2 shows the CC transducer. The output level of the CC transducer was calibrated with the artificial mastoid (type 4930, Rion Co, Ltd) in the same manner as BC. In the calibration of the BC transducer, it is fixed to the artificial mastoid with the fixation force of $5.4 \mathrm{~N}$, which is the same as the fixation to the mastoid for the threshold measurement. In contrast, the CC transducer was held in place by a combination of its own weight and the stiffness of the conchal cartilage. The CC transducer weighs $6 \mathrm{~g}$, and the fixation force, excluding the stiffness of the conchal cartilage, was estimated to be approximately $0.06 \mathrm{~N}$. The force exerted by the stiffness of the conchal cartilage is similarly relatively low. However, the transducer has to be tightly fixed to the artificial mastoid in order to measure the force level. Thus, the CC transducer was also fixed to the artificial mastoid with the fixation force of $5.4 \mathrm{~N}$ in the same manner as the $\mathrm{BC}$ transducer. The output level of CC was represented in hearing level based on ISO 389-3:1994 [18]. The fixation force is an important factor for the sound transmission via BC [19-20]. Because the CC transducer was placed on the cavity of the concha with a force much less than 5.4 $\mathrm{N}$, the efficiency of sound conduction from CC transducer to cartilage was expected to be less than that for BC transducer to bone.

\section{RESULTS}

Figure 3 shows the audiograms for the ears with fibrotic aural atresia. All the audiograms show a large airbone gap due to the aural atresia. Figure 4 shows the results of CT. Soft tissue density was observed in the ear canals, implying fibrotic aural atresia. For subject 1 , the bony portion was maintained and fibrotic tissue did not

Table.

Characteristics of patients. Laterality is all right side.

\begin{tabular}{|c|c|c|c|c|}
\hline Subject & Age (yr) & Sex & Cause of Fibrotic Aural Atresia & Condition of Opposite Ear \\
\hline 1 & 10 & $\mathrm{~F}$ & $\begin{array}{l}\text { Reatresia after operation of congenital fibrotic aural } \\
\text { atresia and cholesteatoma in occluded ear canal. }\end{array}$ & Normal \\
\hline 2 & 70 & $\mathrm{~F}$ & Chronic irritation and inflammation. & Chronic otitis media \\
\hline 3 & 47 & M & Operation of carcinoma of ear canal. & Normal \\
\hline 4 & 76 & $\mathrm{~F}$ & Operation of carcinoma of ear canal. & Profoundly deaf \\
\hline 5 & 45 & $\mathrm{~F}$ & Operation of carcinoma of ear canal. & Normal \\
\hline 6 & 74 & M & Operation of carcinoma of ear canal. & Sensorineural hearing loss \\
\hline
\end{tabular}




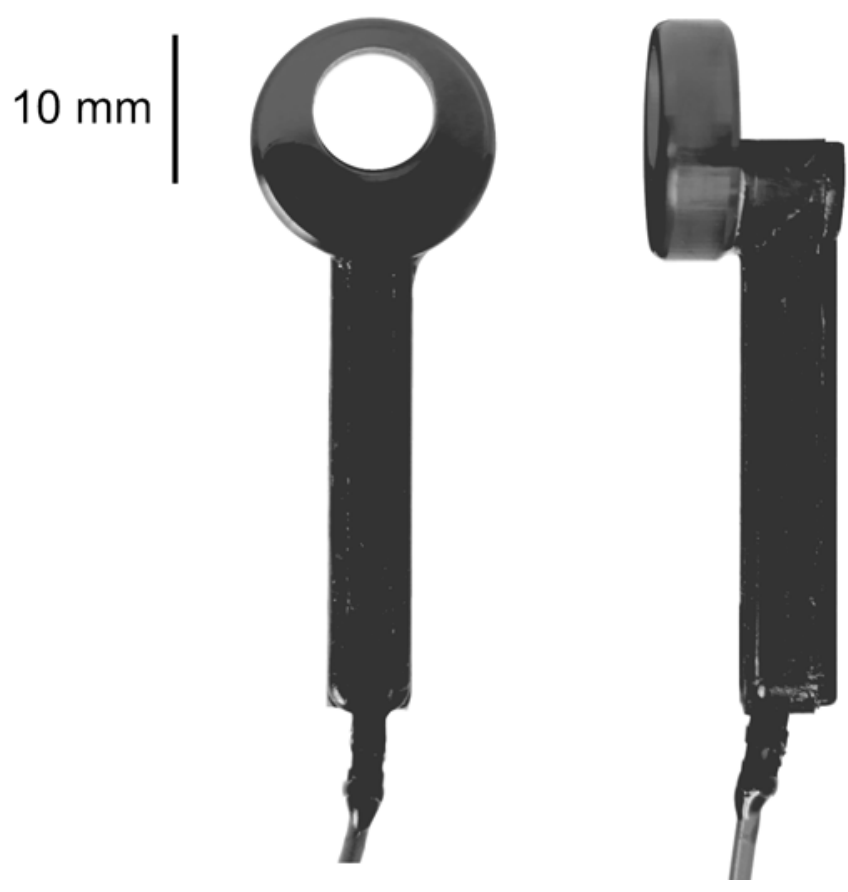

Figure 2.

Cartilage transducer. Transducer comprises piezoelectric bimorph and covering material. Ring made of acrylic acid resin is glued to transducer tip. Outer and inner diameters of ring are 16 and $8 \mathrm{~mm}$, respectively. Its thickness is $5 \mathrm{~mm}$. Total weight of transducer is $6 \mathrm{~g}$.

exist in the bony portion. In contrast, for subject 2, the bony portion was filled with fibrotic tissue induced by irritation and inflammation. For subjects 3, 4, 5, and 6, the bony portion of the ear canal was resected in the operation of carcinoma of the ear canal. With regard to the connection between occluding fibrotic tissue and ossicles, the CT scans for subjects 2, 4, 5, and 6 show a substantial connection of occluding fibrotic tissue with the ossicles, implying the presence of a fibrotic tissue pathway. There is no such connection evident in the CT scans for subjects 1 and 3.

Figure 5 shows the comparison of BC and CC thresholds. In the ears with a fibrotic tissue pathway (subjects 2 , 4,5 , and 6), the CC thresholds were lower than the BC thresholds at frequencies of 0.5 and $1.0 \mathrm{kHz}$. At $2.0 \mathrm{kHz}$, no significant difference was observed between the BC and CC thresholds. At $4.0 \mathrm{kHz}$, the BC threshold was lower in subjects 2,4 , and 5 . In the ears without a fibrotic tissue pathway (subjects 1 and 3), the CC thresholds were
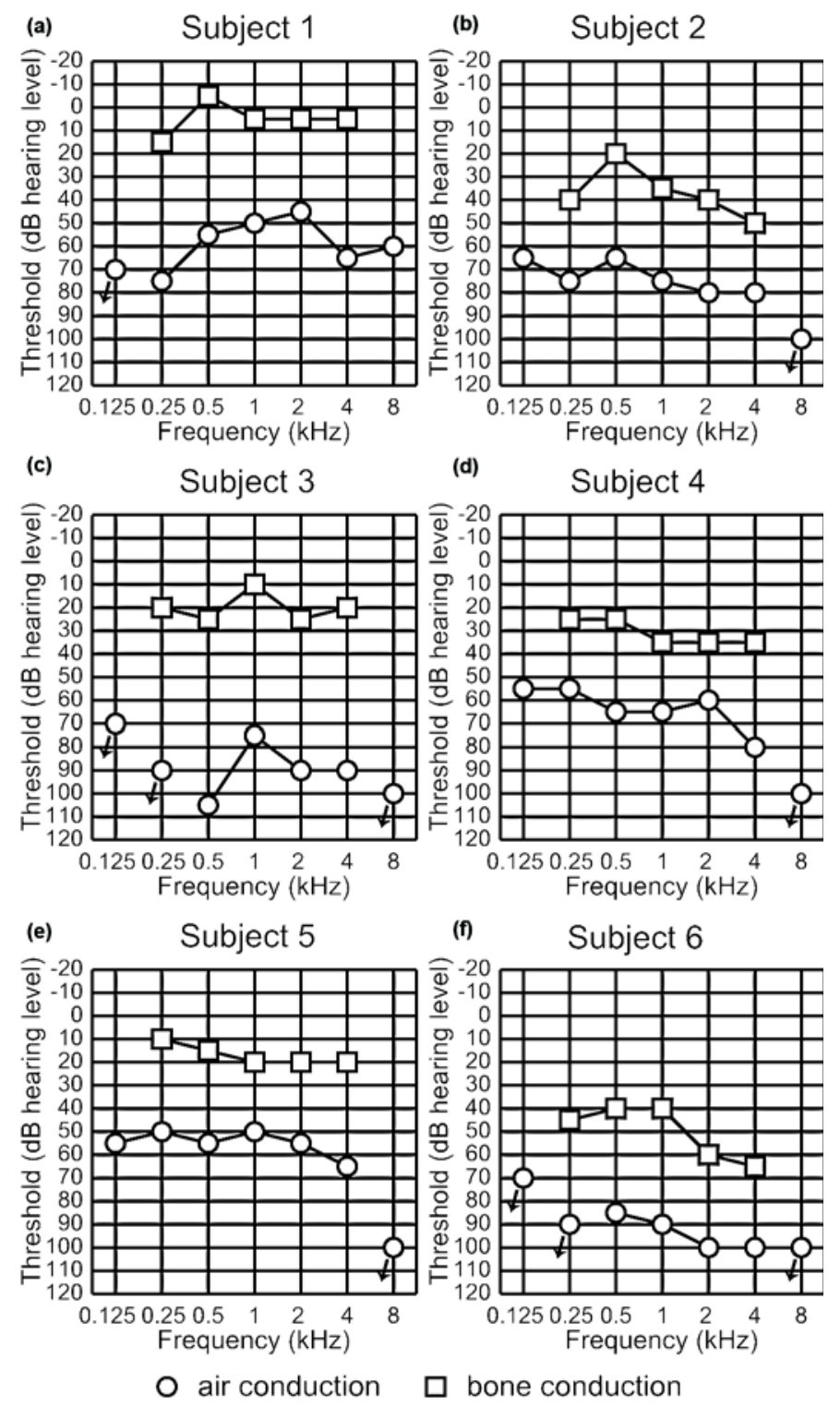

Figure 3.

Audiograms in (a)-(f) six subjects. Arrows show that threshold was higher than masked level. It was not determined within current maximum output level.

lower than the $\mathrm{BC}$ thresholds at $0.5 \mathrm{kHz}$ but not at higher frequencies.

\section{DISCUSSION}

The main hypothesis is supported in that ears with a fibrotic tissue pathway, as determined by the CT scans, showed lower CC thresholds than BC thresholds at 
(a) Subject 1
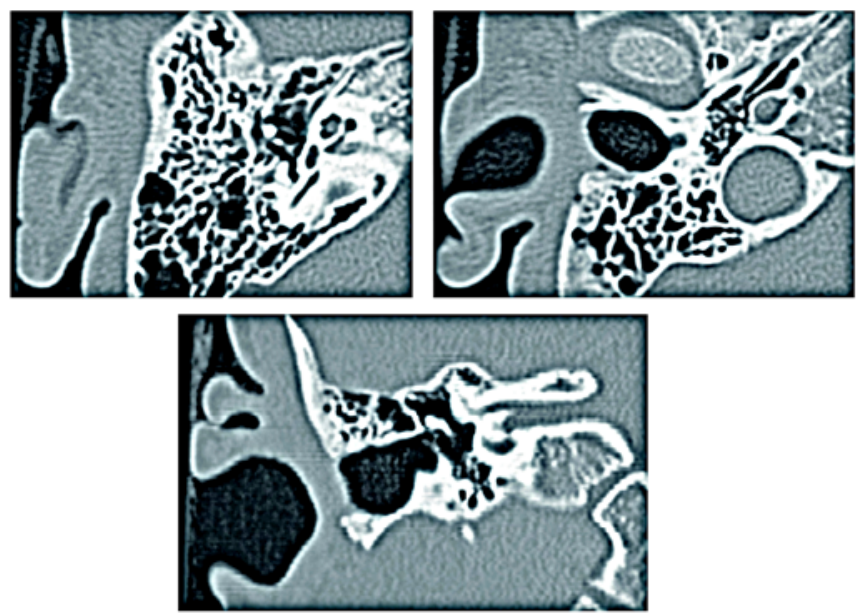

(c) Subject 3
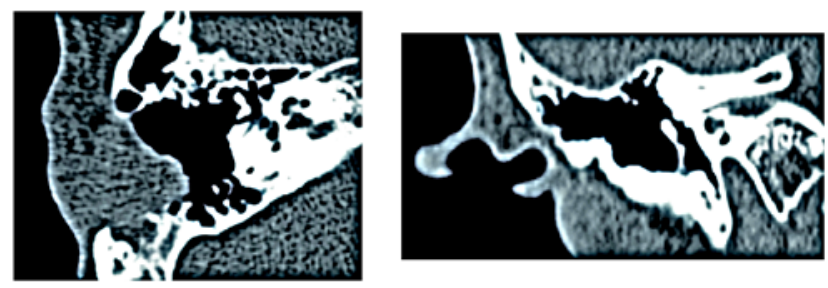

(e) Subject 5

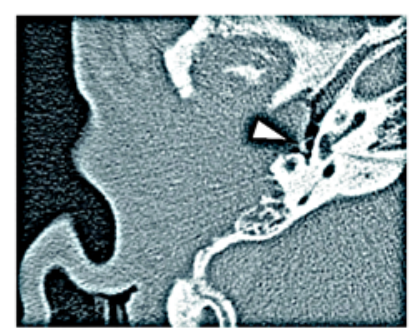

(b) Subject 2
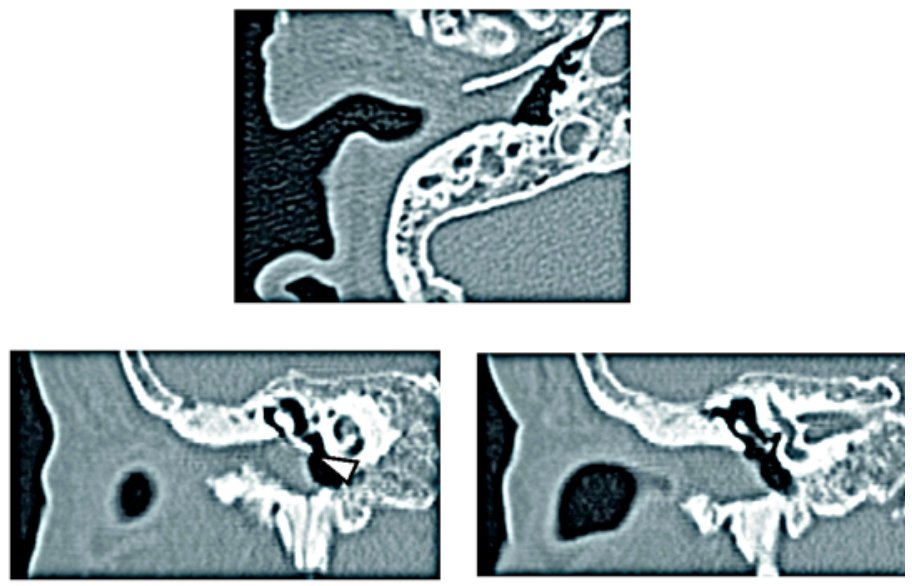

(d) Subject 4
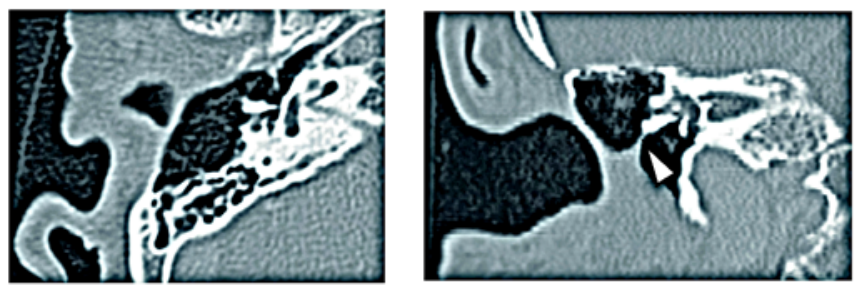

(f) Subject 6
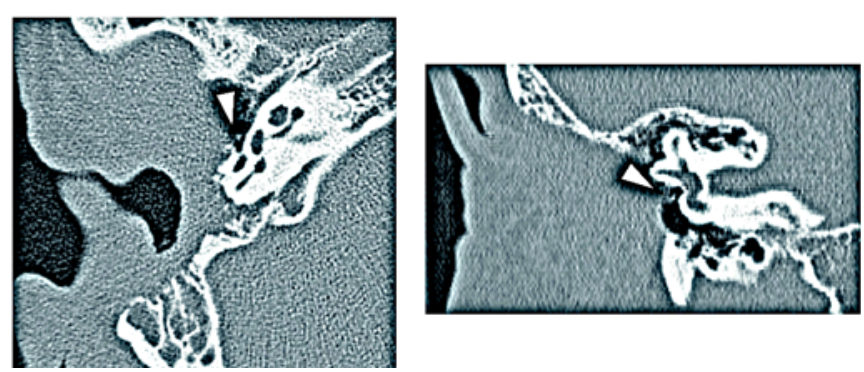

Figure 4.

Results of computed tomography in (a)-(f) six subjects. Triangles indicate connection of fibrotic tissue to ossicles.

frequencies below $2.0 \mathrm{kHz}$. We ague that the connection of the fibrotic tissue to the ossicles created a fourth pathway for CC sound to reach the cochlea (the fibrotic tissue pathway), thereby lowering the CC thresholds. Note that the CC thresholds at $4.0 \mathrm{kHz}$ were substantially poorer than those for BC. Our previous study showed low gain at $4 \mathrm{kHz}$ for the prototype CC hearing aid [14]. The current results are consistent with the gain of the prototype CC hearing aid as a function of frequency.
When the fibrotic tissue is not connected to the ossicles, the transmission pathway to the cochlea has to involve the skull bone or the air cavity between the fibrotic tissue and ossicles. In the case of the cartilage BC pathway, the fixation force is an important factor for efficient sound transmission, particularly at high frequencies [1920]. The low fixation force of the CC transducer may account for the poor CC thresholds at high frequencies. In the case of the cartilage AC pathway, airborne sounds 

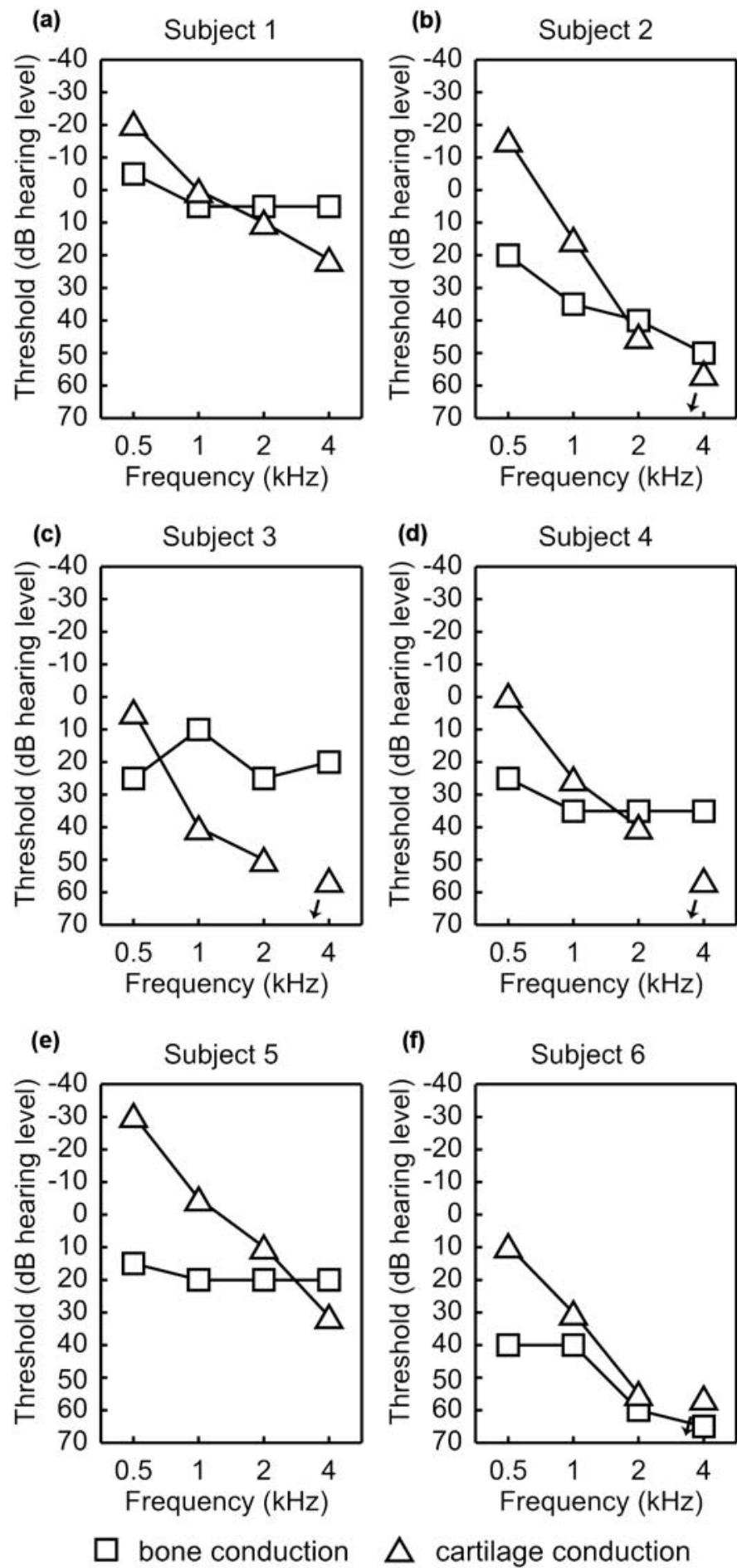

cartilage conduction

Figure 5.

Comparison of threshold in force level between cartilage and bone conduction in (a)-(f) six subjects. Arrows show that threshold was higher than masked level. It was not determined within current maximum output level. from the fibrotic tissue have to vibrate the ossicles without the tympanic membrane. Considering the elevation in thresholds for the ear with the lateralized tympanic membrane [21], sound transmission without a fibrotic tissue pathway is not efficient.

Despite the inefficient transmission without a fibrotic tissue pathway, the CC threshold at $0.5 \mathrm{kHz}$ was lower than that of BC. A possible explanation for the low CC threshold at $0.5 \mathrm{kHz}$ is the occlusion effect. When the ear canal is occluded, a low frequency resonance is introduced such that the threshold for airborne sounds in the canal is lowered in the region of 0.4 to $1.3 \mathrm{kHz}$ [22]. Several factors contribute to the measured CC threshold, and it is not clear which is the dominant factor as a function of frequency. The findings of this study identify a factor that has not been considered in previous investigations, that of a fibrotic tissue pathway in ears with fibrotic aural atresia.

The current findings demonstrated the function of a fibrotic tissue pathway. An ear in which a fibrotic tissue pathway is present has characteristics that are advantageous with respect to the development of an improved CC hearing aid. Compared with AC, sound is delivered by vibrating the aural cartilage, which is not mediated by the air. The acoustic feedback resulting from the impedance mismatch between the air and fibrotic tissue is substantially less than that for an anatomically normal ear. As a consequence, the gain of the hearing aid can be greater for CC than for conventional AC before the onset of uncontrolled acoustic feedback (whistling). Compared with BC, the lower CC thresholds indicate more efficient sound transmission at low to middle frequencies. Vibration of the skull bone is not needed for sound transmission in CC. The output level from the CC transducer is sufficient if it can vibrate the aural cartilage and fibrotic tissue. For this application, the smaller size and lower weight of the CC transducer relative to a $\mathrm{BC}$ transducer are significant advantages. A more substantial advantage is that the fixation force for the CC transducer is about one hundredth of that required for a $\mathrm{BC}$ transducer $(0.06 \mathrm{~N}$ vs $5.4 \mathrm{~N})$. The large fixation force required for $\mathrm{BC}$ transducers is a major source of discomfort with BC hearing aids. Sound transmission in bone is more efficient than in cartilage, which has both advantages and disadvantages. For example, attenuation of sound across the skull is small, resulting in significant transcranial stimulation in a BC hearing aid [23-24]. Crossover stimulation results in additional stimulation of the cochlea contralateral to the ear with the BC 
transducer, thereby reducing the efficacy of binaural hearing [25]. In contrast with the fibrotic tissue pathway, because the force levels at the thresholds for CC were lower than those for BC, the transmission of CC sound is dominantly mediated by not the skull bone but the fibrotic tissue that connects to the ipsilateral cochlea. Consequently, CC sound is perceived by the ipsilateral ear with negligible crossover to the contralateral ear. A binaural CC hearing aid can thus maintain the benefits of binaural hearing, unlike the loss of these benefits with a binaural BC hearing aid [13].

\section{CONCLUSIONS}

In the ear with fibrotic aural atresia, the connection of the fibrotic tissue to the ossicles contributes to more efficient sound transmission by means of CC. In the presence of this fibrotic tissue pathway, CC is more efficient than BC while also providing advantages over BC in terms of transducer weight, substantially smaller fixation force, and greater convenience and comfort. The development of hearing devices using CC can contribute to rehabilitation, particularly in patients with fibrotic aural atresia.

Whereas it is recognized that the incidence of aural atresia is relatively low, with an estimated annual incidence of 0.6 cases per 100,000 inhabitants [26], the estimated number of new cases per year in the United States is 2,000, which is not an insignificant number. It is also likely that veterans with hearing damage resulting from blast injuries will have a significantly higher incidence of acquired aural atresia as a result of damage to the ear and related surgical intervention.

\section{ACKNOWLEDGMENTS}

\author{
Author Contributions: \\ Study concept and design: T. Nishimura, H. Hosoi. \\ Acquisition of data: C. Morimoto, O. Saito, F. Fukuda. \\ Analysis and interpretation of data: R. Shimokura, T. Yamanaka. \\ Drafting of manuscript: C. Morimoto, T. Nishimura. \\ Study supervision: H. Hosoi.
}

Financial Disclosures: The authors have declared that no competing interests exist.

Funding/Support: This material was based on work supported by a Health and Labour Science Research Grant for the Sensory and Communicative Disorders from the Ministry of Health, Labour, and Welfare, Japan. This study was also supported by Japan Society for the
Promotion of Science KAKENHI Grants-in-Aid for Scientific Research (grant 23791924).

Additional Contributions: We thank Dr. Harry Levitt (Professor Emeritus of the City University of New York) for his invaluable help and Mr. Takashi Iwakura and Mr. Kyoji Yoshikawa (Rion Co, Ltd) for development of the CC experiment device.

Institutional Review: The ethics committee of Nara Medical University reviewed and approved this research. All participants provided informed consent.

Participant Follow-Up: The authors do not plan to inform the participants of the publication of this study due to a lack of contact information.

\section{REFERENCES}

1. Mylanus EA, van der Pouw KC, Snik AF, Cremers CW. Intraindividual comparison of the bone-anchored hearing aid and air-conduction hearing aids. Arch Otolaryngol Head Neck Surg. 1998;124(3):271-76. [PMID:9525510] http://dx.doi.org/10.1001/archotol.124.3.271

2. Dillon H. Hearing aids. New York (NY): Thieme; 2001.

3. De la Cruz A, Teufert KB. Congenital aural atresia surgery: Long-term results. Otolaryngol Head Neck Surg. 2003; 129(1):121-27. [PMID:12869927] http://dx.doi.org/10.1016/S0194-5998(03)00531-X

4. Moon IJ, Cho YS, Park J, Chung WH, Hong SH, Chang SO. Long-term stent use can prevent postoperative canal stenosis in patients with congenital aural atresia. Otolaryngol Head Neck Surg. 2012;146(4):614-20.

[PMID:22020788] http://dx.doi.org/10.1177/0194599811426257

5. Jacobsen N, Mills R. Management of stenosis and acquired atresia of the external auditory meatus. J Laryngol Otol. 2006;120(4):266-71. [PMID:16623969] http://dx.doi.org/10.1017/S0022215106000272

6. Magliulo G. Acquired atresia of the external auditory canal: Recurrence and long-term results. Ann Otol Rhinol Laryngol. 2009;118(5):345-49. [PMID:19548383]

7. Håkansson BE, Carlsson PU, Tjellström A, Lidén G. The bone-anchored hearing aid: Principal design and audiometric results. Ear Nose Throat J. 1994;73(9):670-75. [PMID:7988397]

8. Snik AF, Mylanus EA, Cremers CW. The bone-anchored hearing aid compared with conventional hearing aids. Audiologic results and the patients' opinions. Otolaryngol Clin North Am. 1995;28(1):73-83. [PMID:7739870]

9. House JW, Kutz JW Jr. Bone-anchored hearing aids: Incidence and management of postoperative complications. Otol Neurotol. 2007;28(2):213-17. [PMID:17255890] http://dx.doi.org/10.1097/MAO.0b013e31802c74c4

10. Hobson JC, Roper AJ, Andrew R, Rothera MP, Hill P, Green KM. Complications of bone-anchored hearing aid implantation. J Laryngol Otol. 2010;124(2):132-36. 
JRRD, Volume 51, Number 2, 2014

\section{[PMID:19968889]}

http://dx.doi.org/10.1017/S0022215109991708

11. Hosoi $\mathrm{H}$, inventor. Approach in the use of cartilage conduction speaker. Japanese patent 4,541,111. 2004 Nov 17.

12. Hosoi H, Yanai S, Nishimura T, Sakaguchi T, Iwakura T, Yoshino K. Development of cartilage conduction hearing aid. Arch Mater Sci Eng. 2010;42(2):104-10.

13. Shimokura R, Hosoi H, Iwakura T, Nishimura T, Matsui T. Development of monaural and binaural behind-the-ear cartilage conduction hearing aids. Appl Acoust. 2013;74(11): 1234-40. http://dx.doi.org/10.1016/j.apacoust.2013.04.013

14. Nishimura T, Hosoi H, Saito O, Miyamae R, Shimokura R, Matsui T, Iwakura T. Benefit of a new hearing device utilizing cartilage conduction. Auris Nasus Larynx. 2013; 40(5):440-46. [PMID:23395550] http://dx.doi.org/10.1016/j.anl.2012.12.003

15. Lightfoot GR. Air-borne radiation from bone conduction transducers. Br J Audiol. 1979;13(2):53-56. [PMID:486812]

16. Shipton MS, John AJ, Robinson DW. Air-radiated sound from bone vibration transducers and its implications for bone conduction audiometry. Br J Audiol. 1980;14(3):86-99. [PMID:7417729]

17. International Organization for Standardization. ISO 3891:1998. Acoustics-Reference zero for the calibration of audiometric equipment-Part 1: Reference equivalent threshold sound pressure levels for pure tones and supraaural earphones. Geneva (Switzerland): International Organization for Standardization; 1998.

18. International Organization for Standardization. ISO 3893:1994. Acoustics-Reference zero for the calibration of audiometric equipment-Part 3: Reference equivalent threshold force levels for pure tones and bone vibrators. Geneva (Switzerland): International Organization for Standardization; 1994.

19. Nilo ER. The relation of vibrator surface area and static application force to the vibrator-to-head coupling. J Speech Hear Res. 1968;11(4):805-10. [PMID:5719235]

20. Lau CC. The effect of coupling force on bone conduction audiometry. Br J Audiol. 1986;20(4):261-68. [PMID:3790771]
21. Sperling NM, Kay D. Diagnosis and management of the lateralized tympanic membrane. Laryngoscope. 2000;110(12): 1987-93. [PMID:11129006] http://dx.doi.org/10.1097/00005537-200012000-00001

22. Stenfelt S, Wild T, Hato N, Goode RL. Factors contributing to bone conduction: The outer ear. J Acoust Soc Am. 2003; 113(2):902-13. [PMID:12597184] http://dx.doi.org/10.1121/1.1534606

23. Stenfelt S, Goode RL. Bone-conducted sound: Physiological and clinical aspects. Otol Neurotol. 2005;26(6):1245-61. [PMID:16272952] http://dx.doi.org/10.1097/01.mao.0000187236.10842.d5

24. Stenfelt S. Bilateral fitting of BAHAs and BAHA fitted in unilateral deaf persons: acoustical aspects. Int $\mathrm{J}$ Audiol. 2005;44(3):178-89. [PMID:15916119]

25. Agterberg MJ, Hol MK, Cremers CW, Mylanus EA, van Opstal J, Snik AF. Conductive hearing loss and bone conduction devices: Restored binaural hearing? Adv Otorhinolaryngol. 2011;71:84-91. [PMID:21389708] http://dx.doi.org/10.1159/000323587

26. Becker BC, Tos ML. Postinflammatory acquired atresia of the external auditory canal: Treatment and results of surgery over 27 years. Laryngoscope. 1998;108(6):903-7. [PMID:9628508] http://dx.doi.org/10.1097/00005537-199806000-00021

Submitted for publication May 31, 2013. Accepted in revised form September 18, 2013.

This article and any supplementary material should be cited as follows:

Morimoto C, Nishimura T, Hosoi H, Saito O, Fukuda F, Shimokura R, Yamanaka T. Sound transmission by cartilage conduction in ear with fibrotic aural atresia. J Rehabil Res Dev. 2014;51(2):325-32.

http://dx.doi.org/10.1682/JRRD.2013.05.0128

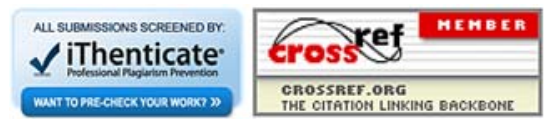

